\title{
Dose Management for X-Ray and CT: Systematic Comparison of Exposition Values from Two Institutes to Diagnostic Reference Levels and Use of Results for Optimisation of Exposition
}

\section{Dosismanagement für konventionelles Röntgen und CT: Systematischer Vergleich der Expositionswerte zweier radiologischer Institute mit den diagnostischen Referenzwerten und Verwendung der Ergebnisse zur Optimierung der Strahlenexposition bei diagnostischen Untersuchungen}

Authors

Affiliations
S. Schäfer ${ }^{1}$, E Alejandre-Lafont ${ }^{1}$, T. Schmidt ${ }^{2}$, E. R. Gizewski ${ }^{3}$, M. Fiebich ${ }^{4}$, G. A. Krombach ${ }^{1}$

Radiology, University Hospital Giessen

Neuroradiology, University Hospital Giessen

3 Neuroradiology, University Hospital Insbruck

${ }^{4}$ Institute of Medical Physics and Radiation Protection, University of Applied Sciences, Giessen
Key words

- reference levels

- dose monitoring

- dose management

- dose optimization

received 18.6.2013

accepted $\quad 9.12 .2013$

Bibliography

DOI http://dx.doi.org/

10.1055/s-0033-1356425

Published online: 1.4.2014

Fortschr Röntgenstr 2014; 186:

785-794 @ Georg Thieme

Verlag KG Stuttgart · New York

ISSN 1438-9029

\section{Correspondence}

Prof. Gabriele Anja Krombach

Klinik für Diagnostische und Interventionelle Radiologie, Universitätsklinikum Gießen, Justus-Liebig Universität Gießen Klinikstraße 33

35392 Gießen

Tel.: ++ 49/641/98541800

Fax: ++49/641/98541809

gabriele.krombach@

uniklinikum-giessen.de

\section{Abstract}

$\nabla$

Purpose: In 2 institutions exposure values were evaluated and compared with the 2010 updated diagnostic reference levels (DRL) and possibilities for decreasing the dose assessed. Materials and Methods: Mean exposure values obtained during a 3-month period were calculated for all modalities (X-ray: imaging plate system and digital detector; dual-source 64- and 16- slice spiral CT) as well as examination types were compared to old diagnostic reference levels in addition to DRLs introduced in 2010. Then 10 examinations of all modalities and types were accompanied by a medical physicist and optimized stepwise if necessary.

Results: The mean values of X-ray examinations were above DRL. All accompanied examinations were beyond DRL except lateral lumbar spine (LSP) and lateral thoracic X-ray, which were elevated due to statistical outliers from morbidly obese patients or patients with metallic implants. For a-p LSP tube voltage was increased. While image quality was maintained, dose area product (DAP) was reduced by $50 \%$ to $123 \pm 61 \mathrm{cGy} \cdot \mathrm{cm}^{2}$ for LSP a-p and $30 \%$ for lateral LSP to $229 \pm 116 \mathrm{cGy} \cdot \mathrm{cm}^{2}$. For CT examinations, dose was below DRL. Accompanied examinations of the lumbar spine performed on a 16-slice spiral CT demonstrated a result $68 \%$ above DRL with dose length product (DLP) of $840 \pm 252 \mathrm{cGy} \cdot \mathrm{cm}$. For optimization, pitch and tube voltage were stepwise increased and DLP reduced below DRL.

Conclusion: Systematic analysis of our internal exposure values on the occasion of adaptation of DRL is crucial for prompt detection of exceeded values independently from assessment by the responsible authority and in- itiation of proper measures for decreasing exposure dose. Hereby active dose management is attained.

Key Points:

- Analysis of exposure values for high data volumes obtained from the Radiology Information System (RIS) is possible independent of weight.

- Summation of small groups of patients with different weights might result in high exposure values (DRL $70 \mathrm{~kg}$ ).

- If high exposure values are observed in small groups of patients, individual analysis of examinations is mandatory.

- Active dose management can be obtained by an analysis of average exposure of all examinations obtained during a specific observation period.

- Potential for optimization of exposure values might be possible even they fall below DRL.

Citation Format:

- Schäfer S, Alejandre-Lafont E, Schmidt T et al. Dose Management for X-Ray and CT: Systematic Comparison of Exposition Values from two Institutes to Diagnostic Reference Levels and Use of Results for Optimisation of Exposition. Fortschr Röntgenstr 2014; 186: 785-794

\section{Zusammenfassung \\ $\nabla$}

Ziel: Es sollten die Dosiswerte hinsichtlich der 2010 angepassten diagnostischen Referenzwerte (DRW) überprüft und Möglichkeiten zur Dosiseinsparung evaluiert werden.

Material und Methoden: Aus den Expositionswerte von 3 Monaten wurden für alle Modalitäten Mittelwerte gebildet und mit den alten und 2010 aktualisierten DRW verglichen. Je 10 Unter- 
suchungen der unterschiedlichen Arten wurden von einem Medizinphysiker begleitet und wenn nötig optimiert.

Ergebnisse: Die ermittelten Expositionswerte lagen unterhalb der DRW. Die begleiteten Untersuchungen, mit Ausnahme der anterior-posterior (a. p.) Aufnahme der LWS mit dem Speicherfoliensystem (Dosisflächenprodukt (DFP) $246 \pm 203 c G y \cdot \mathrm{cm}^{2} ; 7 \%$ über den DRW) und der lateralen Thoraxaufnahmen am digitalen Detektor (71 $\pm 89 \mathrm{cGy} \cdot \mathrm{cm}^{2} ; 29 \%$ über den DRW), die durch Ausreißer bei metallischen Implantaten oder Adipositas erhöht waren, lagen ebenfalls unter den DRW. Für a.-p. Untersuchungen der LWS wurde die Röhrenspannung erhöht. So konnte bei gleicher Bildqualität eine Reduktion das Dosisflächenprodukt (DFP) auf $123 \pm 61 \mathrm{cGy} \cdot \mathrm{cm}^{2}$ (LWS a.-p.) und $229 \pm 116 \mathrm{cGy} \cdot \mathrm{cm}^{2}$ (lateral) erzielt werden. Für die CT lagen die ermittelten Werte unterhalb der neuen DRW. Für die begleiteten Untersuchungen wurden für die LWS am 16-Zeilen-CT mit $840 \pm 252 \mathrm{mGy} \cdot \mathrm{cm}$ Dosislängenprodukt (DLP) Werte, die die DRW überstiegen, ermittelt. Bei der Optimierung wurden Pitch und Röhrenspannung schrittweise erhöht, sodass das DLP unter die DRW reduziert werden konnte.

Schlussfolgerung: Die systematische Analyse der eigenen Expositionswerte anlässlich der Anpassung der DRW ist entscheidend, um Überschreitungen unabhängig von der Prüfung durch die ärztliche Stelle zeitnah zu erkennen und geeignete Maßnahmen zur Senkung der Expositionswerte einzuleiten. Hierdurch wird ein aktives Dosismanagement erreicht.

\section{Introduction}

$\nabla$

Compared to other fields, radiology has significantly benefited from the introduction of new methods and innovationbased improvement of established procedures. One aspect of this is the continuous reduction of radiation exposure during X-ray imaging since its implementation in clinical practice. Compared with dosages in the early years, modern $\mathrm{X}$-ray equipment has reduced radiation doses for almost all examination regions by more than $500 \%[1,2]$.

In Germany, legislation regulates radiation exposure protection for patients and examiners through the X-Ray Ordinance (RöV) established as federal law. The German X-ray Ordinance went into effect on September 1, 1973 and was revised on January 8, 1987. For a long time radiation exposure for diagnostic purposes only followed the ALARA principle (As Low As Reasonably Achievable). Standard dosage values or diagnostic reference levels did not exist. For the first time, the International Commission on Radiological Protection (ICRP) recommended the application of dose reference levels in 1996 [3]. A year later, EURATOM (European Atomic Energy Community), which likewise addresses the requirements of radiation protection anchored this concept in a patient protection directive [4] which required all EU member states to include diagnostic reference levels (DRL) into their respective national legislation. Dose reference levels are defined as dose values which may not be exceeded during diagnostic applications on patients using standard dimensions or standard phantoms with commonly defined equipment.

In 1999 the European Commission finally issued a guideline with exact recommendations for the introduction of standard dose levels which define the weight of the "standard patient" as $70 \mathrm{~kg} \pm 3 \mathrm{~kg}$. In addition, the Commission recommended using an average dose value of several unselected patients, at least 10 in number, as a substitute for the dose for a standard patient as well as the introduction of uniform diagnostic reference levels in the EU [5]. In Germany, diagnostic reference levels were first introduced in the revision of the X-ray Ordinance dated June 18, 2002, and was thus included into national law [6].

Since then, according to paragraph 16, sec. 1, sentence 3 of the X-ray Ordinance, diagnostic reference levels must be established for radiation exposure during examinations of humans. Sentence 1 of the same paragraph specifies that the reference values must be created and published by the Federal Office for Radiation (BfS). This was published for the first time on August 5, 2003 in the German Federal Gazette (Bundesanzeiger) No. 143 [5]. The DRLs for X-ray images are indicated as dose area product (DAP) values; for CT these are weighted computed tomography dose index values $\left(\mathrm{CTDI}_{\mathrm{W}}\right)$ and dose length product (DLP) values.

The medical authorities review compliance with the diagnostic reference levels and report whenever these levels are "consistently, unjustifiably exceeded" according to paragraph 17a, section 1 sentence 3 no. 2 of the X-Ray Ordinance to the competent state authority, which after a review with the operator together with the medical authority, recommends measures to reduce exposure to radiation.

Further, the BfS is required to regularly update the diagnostic reference levels. This is performed based on operatorsupplied exposure values provided to the BfS by the medical authorities. On June 22, 2010, the BfS updated the diagnostic reference levels for the first time [6]. The new levels are based on the 75th percentile of the distribution of mean values of patient exposure, and for most examinations, they lie below the values set prior to June 22, $2010[7,8]$. Subsequently, operators are now required to review their own DAP values as to whether they meet the new requirements, enact correct measures where necessary and institute activities to comply with the diagnostic reference levels. The experts at the Federal Office for Radiation expect that both the patient dosage as well as the diagnostic reference levels will continue to decline in the long term, thus further reducing the radiation load of the population due to X-ray diagnostics [8].

Further, the X-ray Ordinance contains the explicit requirement to keep radiation exposure as low as possible, taking into account state-of-the-art technology and considering all circumstances of individual cases.

The purpose of this study was to review current dose values with respect to diagnostic reference levels, to identify examination types and equipment to determine the need for optimization, and assess whether mean exposure levels could be reduced using simple optimization activities. This review was performed in two university radiological institutes (Diagnostic and Interventional Radiology and Neuroradiology) which at the time of data acquisition operated according to the pavilion principle, i.e. at two different locations.

\section{Materials and Methods}

$\nabla$

Anonymized exposure values were taken from the Radiological Information System (RIS) for a time period three months prior to the analysis of all modalities and examina- 
tions. All data were entered manually into the RIS directly after the respective examinations. Weight data were in part taken from the KIS clinic information system. The investigation was performed at four different sub-units of the pavilion system. Procedures for standard X-rays used two devices: An imaging plate system (Agfa DX-S, Agfa, Louvain, Belgium) was used for orthopedic patients; the other was equipped with a digital detector (Bucky Diagnost CS, Philips, Best, Netherlands) and was used for surgery patients. In addition data from two different $\mathrm{CT}$ units were evaluated, a 64-slice dual-source device for whole body examinations (SOMATOM Definition, Siemens, Erlangen, Germany and a 16-slice spiral CT scanner (LightSpeed 16, GE Healthcare Germany, Munich), used for neuroradiological examinations.

Mean values were established separately by examination type and device; old and new diagnostic reference levels were compared and analyzed to determine whether the new DRLs were exceeded. Mean values were selected as a parameter, since their use meet the requirements of the guidelines of the "medical and dental authority". In addition, outliers extending two standard deviations beyond the mean value were included in the data sets. These examinations were reviewed by two experienced observers (20 and 22 years' experience) who assessed the images with respect to explainable exposure values due to obesity or metallic implants, as well as errors in the images. The weight of these patients was taken from the clinic information system (KIS) for evaluation; excluded were patients whose weight exceeded by at least $50 \mathrm{~kg}$ the standard $70 \mathrm{~kg}$ patient weight according to EURATOM Patient Protection Directive, since such patients would negatively affect the mean value. For patients without weight data in the KIS, conclusions were drawn with respect to patient weight based on the X-ray and CT images; morbidly obese patients were excluded from the evaluation. In total, approx. less than one percent of the data sets was excluded from the analysis.
Then 10 examinations using different modalities were accompanied by a medical physicist in order to evaluate the dose values with respect to the patients (size, weight, ability to cooperate, etc.). The examination parameters and DAP were recorded. In particular, examination types for which diagnostic reference levels were available were included. Since various departments in the pavilion system perform different tasks, each examination type is not performed in every department; correspondingly, data could be obtained only for the respective examination types performed. Based on these values, recommendations were developed for the optimization of radiation exposure while maintaining image quality. In the case of examinations in which the mean dose value exceeded the new diagnostic reference levels, physicians, physicists and MTRAs worked together to find optimization possibilities and implemented them.

\section{Results \\ $\nabla$}

\section{Dose Determination Results}

The evaluation indicated high RIS data quality. Incorrect inputs were identified in only a few exceptions. O Fig.1, - Table 1 provide an overview of the mean values for $\mathrm{X}$-ray images using the imaging plate system and the unit with digital detector, using the dose values within a threemonth time frame. The mean values for both X-ray systems lay significantly below the old and new diagnostic reference levels for all examinations. Thus, on average, the values for the imaging plate system were approx. $62 \%$ of the new diagnostic reference levels and $39 \%$ of the old diagnostic reference levels. Values for the unit with the digital detector were approx. $56 \%$ of the new levels and $33 \%$ of the old. The unit with the digital detector exhibited somewhat higher exposure values compared to imaging plate radiography. An incompletely adapted parameter selection was identified as the source of this.

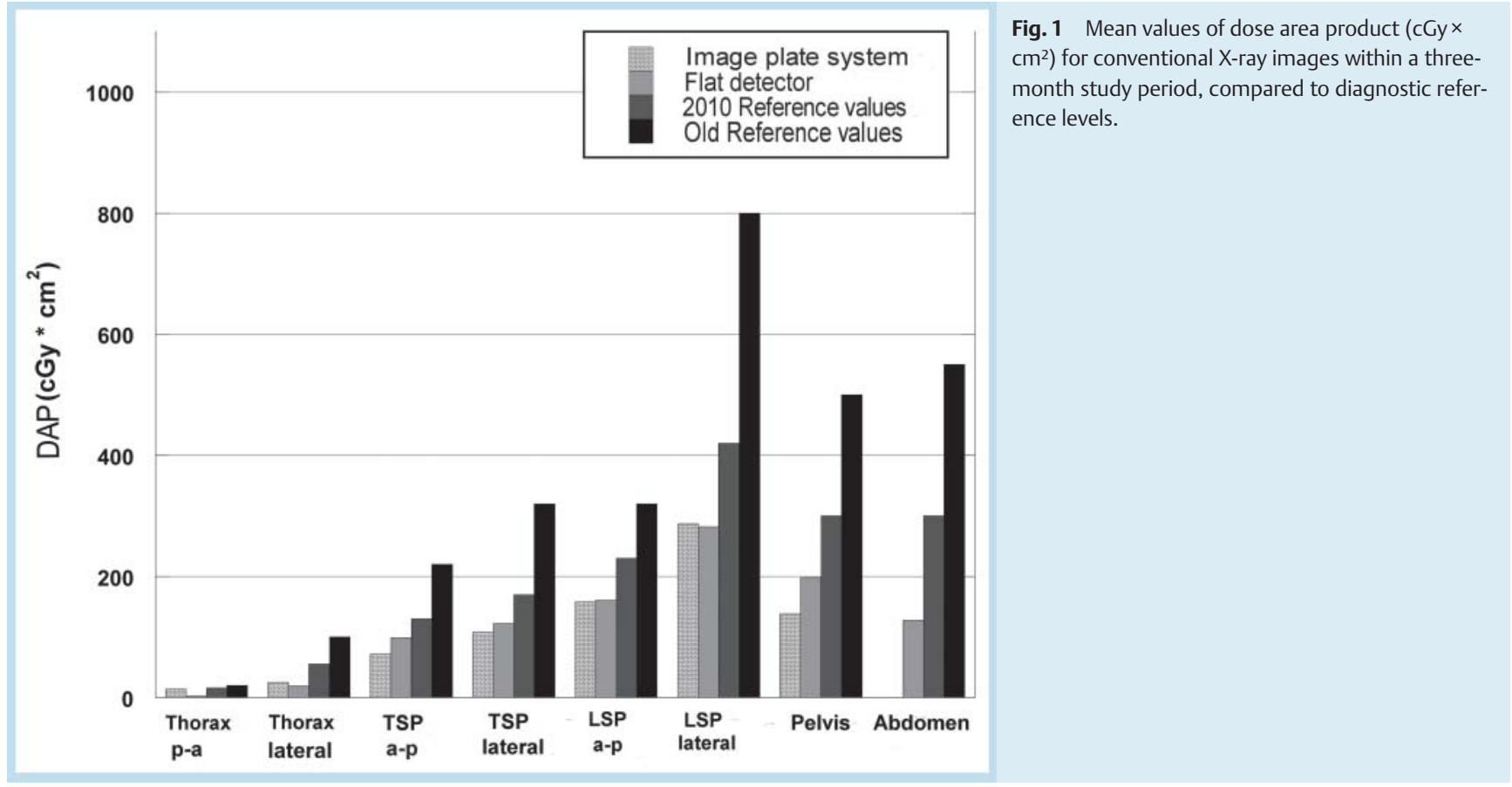


Table 1 Mean exposure values (dose area product $c G y \times \mathrm{cm}^{2}$ ) of X-ray examinations obtained with an imaging plate system and with a digital detector.

\begin{tabular}{|c|c|c|c|c|c|c|c|c|}
\hline \multirow[t]{2}{*}{ examination } & \multicolumn{3}{|c|}{ imaging plate system } & \multicolumn{3}{|c|}{ unit with digital detector } & \multirow{2}{*}{$\begin{array}{l}\text { reference values } \\
\text { introduced in } \\
2010\end{array}$} & \multirow{2}{*}{$\begin{array}{l}\text { old reference } \\
\text { values }\end{array}$} \\
\hline & DAP & $\begin{array}{l}\text { standard } \\
\text { deviation }\end{array}$ & $\begin{array}{l}\text { number of } \\
\text { examinations }\end{array}$ & DAP & $\begin{array}{l}\text { standard } \\
\text { deviation }\end{array}$ & $\begin{array}{l}\text { number of } \\
\text { examinations }\end{array}$ & & \\
\hline thoraxp-a & 14 & 4 & 10 & 3 & 1.8 & 50 & 16 & 20 \\
\hline thorax lateral & 25 & 17 & 10 & 19 & 15.5 & 50 & 55 & 100 \\
\hline TSP a-p & 72 & 67 & 26 & 99 & 22.2 & 44 & 130 & 220 \\
\hline TSP lateral & 108 & 87 & 26 & 122 & 28.3 & 44 & 170 & 320 \\
\hline LSP a-p & 158 & 130 & 149 & 161 & 21.8 & 43 & 230 & 320 \\
\hline LSP lateral & 287 & 170 & 149 & 282 & 42.3 & 43 & 420 & 800 \\
\hline pelvis & 138 & 162 & 375 & 198 & 25.6 & 38 & 300 & 500 \\
\hline abdomen & - & - & - & 128 & 55.3 & 74 & 300 & 550 \\
\hline
\end{tabular}

Table 2 Mean exposure values (dose area product $c G y \times \mathrm{cm}^{2}$ ) of X-ray examinations accompanied by a medical physicist obtained using an imaging plate system and a digital detector.

\begin{tabular}{|c|c|c|c|c|c|c|}
\hline \multirow[t]{2}{*}{ examination } & \multicolumn{2}{|c|}{ imaging plate system } & \multicolumn{2}{|c|}{ unit with digital detector } & \multirow{2}{*}{$\begin{array}{l}\text { reference values } \\
\text { introduced in } 2010\end{array}$} & \multirow[t]{2}{*}{ old reference values } \\
\hline & DAP & standard deviation & DAP & standard deviation & & \\
\hline thoraxp-a & 12 & 6 & 12 & 9.9 & 16 & 20 \\
\hline thorax lateral & 71 & 89 & 28.8 & 11.1 & 55 & 100 \\
\hline TSP a-p & 74 & 87 & 35 & 32.9 & 130 & 220 \\
\hline TSP lateral & 84 & 80 & 59 & 40.1 & 170 & 320 \\
\hline LSP a-p & 246 & 203 & 105 & 149.4 & 230 & 320 \\
\hline LSP lateral & 331 & 176 & 178 & 204.4 & 420 & 800 \\
\hline pelvis & 124 & 6 & 114 & 102.2 & 300 & 500 \\
\hline abdomen & & & 107 & 75.6 & 300 & 550 \\
\hline
\end{tabular}

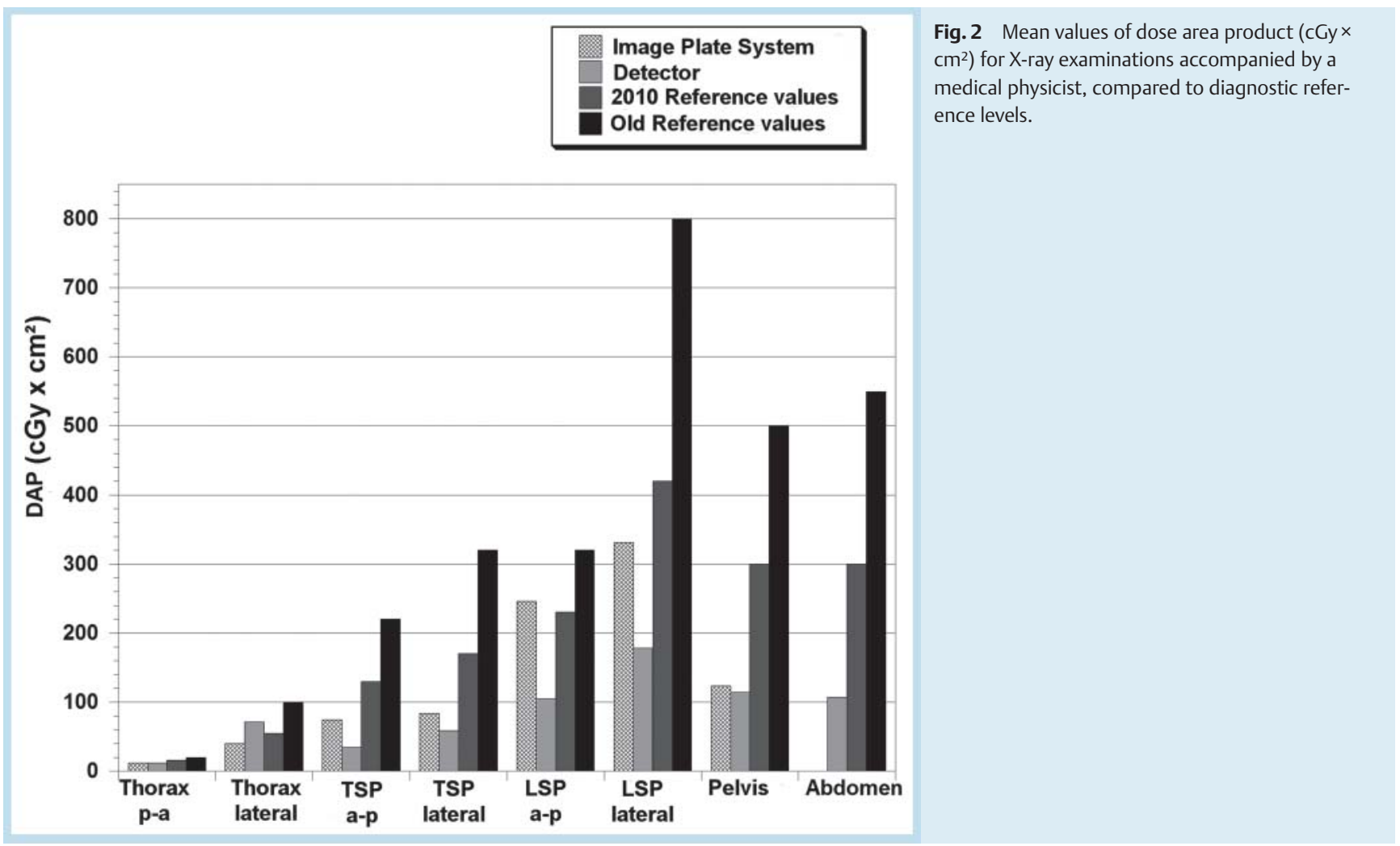

- Fig. 2 shows an overview of the mean values for X-ray images using the imaging plate system and the unit with di- gital detector for the examinations accompanied by a medical radiologist. 
On average, the values lay significantly below the new diagnostic reference levels, with approx. $68 \%$ of the DRLs for the imaging plate system, and $53 \%$ for the unit with the digital detector. In two examination types, however, the new diagnostic reference levels were exceeded, as shown in - Table 2, 5. The dose levels of the a-p (anterior-posterior) examination of the lumbar spine (LSP) with the imaging plate system were somewhat raised and the mean value, $246 \pm 203 \mathrm{cGy} \cdot \mathrm{cm}^{2}$ was approx. $7 \%$ above the new diagnostic reference levels. Further, the dose for lateral thorax images with the imaging plate system significantly exceeded the permitted mean value with $71 \pm 89 \mathrm{cGy} \cdot \mathrm{cm}^{2}$, was $29 \%$ above the new diagnostic reference level. Since the diagnostic reference levels for lateral thorax examinations and the a-p examinations of the lumbar spine were exceeded, the individual images of both examination types were given closer scrutiny.

- Fig. 3,4 show the mean dose levels for the images produced by both CT units for the various examination types

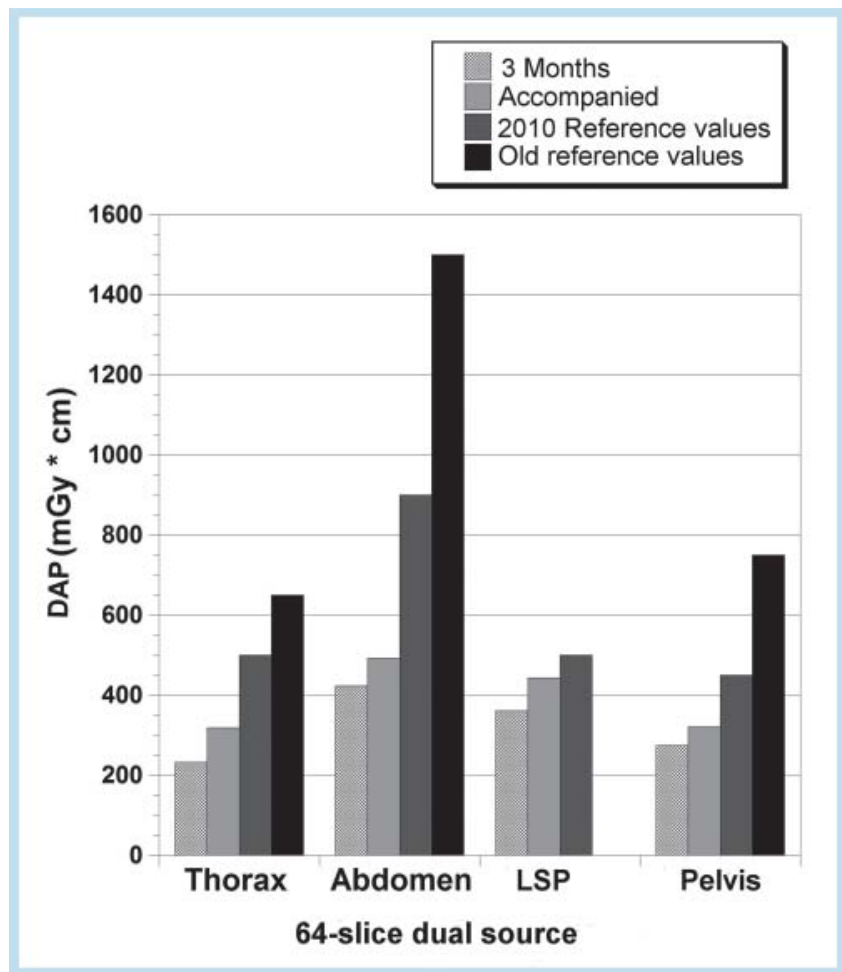

Fig. 3 Mean values of dose length product (DLP) of examinations during the three-month study period as well as examinations accompanied by a medical physicist, obtained using a 64-slice dual source scanner, compared to diagnostic reference levels. taken within the time frame of three months. However, due to an earlier lack of specific diagnostic reference levels for lumbar spine examinations, a comparison of dose levels using old diagnostic reference levels for this examination is not possible.

Without exception, the determined mean dose levels lay below the old and new diagnostic reference levels for the 64 -slice dual source unit ( $\bullet$ Table 3 ). In this instance the dose levels for examinations within the three-month time frame were on average $57 \%$ of the new reference levels and only $34 \%$ of the old levels. Likewise, the examinations accompanied by the medical physicists exhibit lower values than the specified diagnostic reference levels. Compared with dose levels in the investigation time period of three months, these values were on average $70 \%$ of the new levels and $42 \%$ of the old diagnostic reference levels.

The dose levels for the 16-slice spiral CT in the Neuroradiology department for examinations during the three-month time frame were likewise below the DRLs, but with an aver-

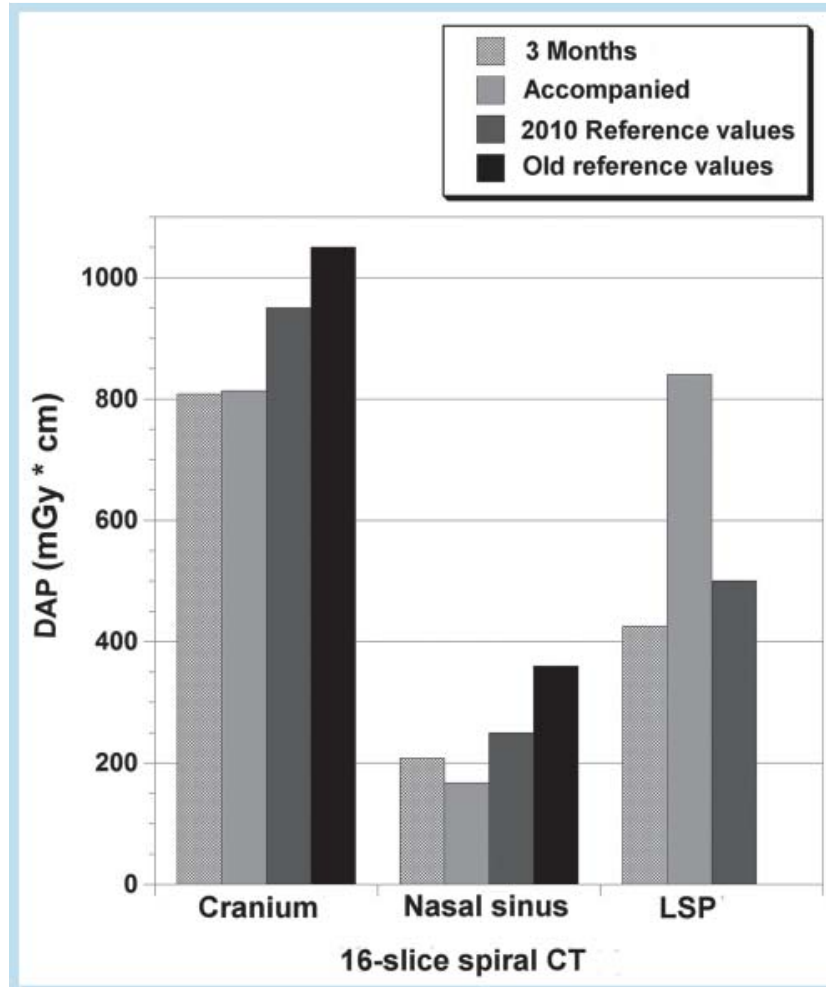

Fig. 4 Mean values of dose length product (DLP) of examinations during the three-month study period and as well as examinations accompanied by a medical physicist, obtained using a 16-slice spiral CT scanner, compared to diagnostic reference levels.

Table 3 Mean exposure values (DLP in $\mathrm{mGy} \times \mathrm{cm}$ ) obtained using a 64-slice dual source CT.

\begin{tabular}{|c|c|c|c|c|c|c|c|c|}
\hline \multirow[t]{2}{*}{ examination } & \multicolumn{3}{|c|}{ 3-month examination time frame } & \multicolumn{3}{|c|}{ accompanied examinations } & \multirow{2}{*}{$\begin{array}{l}\text { reference values } \\
\text { introduced in } \\
2010\end{array}$} & \multirow{2}{*}{$\begin{array}{l}\text { old reference } \\
\text { values }\end{array}$} \\
\hline & DLP & $\begin{array}{l}\text { standard } \\
\text { deviation }\end{array}$ & $\begin{array}{l}\text { number of } \\
\text { examinations }\end{array}$ & DLP & $\begin{array}{l}\text { standard } \\
\text { deviation }\end{array}$ & $\begin{array}{l}\text { number of } \\
\text { examinations }\end{array}$ & & \\
\hline thorax & 233 & 122.5 & 141 & 319 & 137 & 29 & 500 & 650 \\
\hline abdomen & 427 & 225.9 & 169 & 492 & 334 & 11 & 900 & 1500 \\
\hline LSP & 362 & 106.4 & 16 & 444 & 469 & 12 & 500 & - \\
\hline pelvis & 274 & 37 & 9 & 322 & 89 & 4 & 450 & 750 \\
\hline
\end{tabular}


Table 4 Mean exposure values (DLP in $\mathrm{mGy} \times \mathrm{cm}$ ) obtained using a 16-slice spiral CT.

\begin{tabular}{|c|c|c|c|c|c|c|c|c|}
\hline \multirow[t]{2}{*}{ examination } & \multicolumn{3}{|c|}{ 3-month examination time frame } & \multicolumn{3}{|c|}{ accompanied examinations } & \multirow{2}{*}{$\begin{array}{l}\text { reference values } \\
\text { introduced in } \\
2010\end{array}$} & \multirow{2}{*}{$\begin{array}{l}\text { old reference } \\
\text { values }\end{array}$} \\
\hline & DLP & $\begin{array}{l}\text { standard } \\
\text { deviation }\end{array}$ & $\begin{array}{l}\text { number of } \\
\text { examinations }\end{array}$ & DLP & $\begin{array}{l}\text { standard } \\
\text { deviation }\end{array}$ & $\begin{array}{l}\text { number of } \\
\text { examinations }\end{array}$ & & \\
\hline cranium & 808 & 120 & 761 & 814 & 137 & 10 & 950 & 1050 \\
\hline $\begin{array}{l}\text { visceral cranium } \\
\text { (tumor diagnosis) }\end{array}$ & 208 & 119 & 31 & 167 & 128 & 10 & 250 & 360 \\
\hline LSP & 425 & 149 & 27 & 840 & 252 & 13 & 500 & \\
\hline
\end{tabular}

age of approx. $84 \%$ of the new diagnostic reference levels, and $67 \%$ of the old levels, somewhat higher in comparison to the dose levels for the Somatom Definition.

In the examinations on the 16-slice spiral CT accompanied by the medical physicist, the mean dose value of $840.08 \pm$ $252.12 \mathrm{mGy} \cdot \mathrm{cm}$ for the lumbar spine examination significantly exceeded the permitted DRL by about $68 \%$. On the other hand, the dose levels for examinations of the cranium and nasal sinuses were on average $76 \%$ of the new diagnostic reference levels and $62 \%$ of the old levels, i.e. significantly below the specified DRLs. The values for the 16-slice spiral CT are summarized in 0 Table 4. Optimization was performed for this examination type since this device exceeded the reference dose level during the lumbar spine examinations in the accompanying investigations.

\section{Optimization}

The first step toward optimization was to look at the parameters of the selected examinations based on the outliers and view the images. Notable are the wide variations within the two examination types, lying between the highest and lowest values of the data set ( $\bullet$ Table 5, 6). The images with high levels were first checked for possible error sources during the examination, such as faulty collimation. Once this was ruled out, both with respect to the performance of the examination as well as the available images, the images of the accompanied examinations which exhibited excessive exposure levels were then checked for metallic implants or morbid obesity. This was confirmed for all individual images with values lying above the diagnostic reference levels. Examinations with highly elevated exposure levels can occur here such as a DAP value of $757.00 \mathrm{cGy} \cdot \mathrm{cm}^{2}$ for a lumbar spine a-p examination of a patient weighing $145 \mathrm{~kg}$. For this reason it is useful not to include such individual outliers in the study since the definition of standard patient with a weight of $70 \pm 3 \mathrm{~kg}$ is also specified by the European Commission. Without these outliers, the mean value for a lateral thorax examination is calculated to be $29 \pm 10 \mathrm{cGy} \cdot \mathrm{cm}^{2}$, and the mean for an a-p examination of the lumbar spine is $189 \pm 95 \mathrm{cGy} \cdot \mathrm{cm}^{2}$. Both values lie beneath the diagnostic reference level.

In addition, the tube voltage was increased in accordance with the limits recommended by the German Medical Association. The tube voltage for a-p lumbar spine examinations was increased to $75-85 \mathrm{kV}$ (previously $65-75 \mathrm{kV}$ ), and increased to $85-95 \mathrm{kV}$ for lateral lumbar spine examinations (previously $75-85 \mathrm{kV}$ ).
Table 5 Accompanied lateral thorax examinations on the system with the digital detector, exposure values of the 10 examinations and mean value. Tube voltage $125 \mathrm{kV}$.

\begin{tabular}{|c|c|}
\hline tube current $\times$ time $(\mathbf{m A s})$ & dose area product $\left(\mathbf{c G y} \times \mathbf{c m}^{\mathbf{2}}\right)$ \\
\hline 35.0 & 207 \\
\hline 9.0 & 36 \\
\hline 8.7 & 45 \\
\hline 3.5 & 23 \\
\hline 5.7 & 33 \\
\hline 4.9 & 30 \\
\hline 45.0 & 267 \\
\hline 5.8 & 37 \\
\hline 3.6 & 19 \\
\hline 1.9 & 10 \\
\hline Mean 12.3 & Mean 71 \\
\hline
\end{tabular}

Table 6 Accompanied lateral lumbar spine examinations obtained on the imaging plate system; values of the 10 accompanied examinations and mean value from these examinations.

\begin{tabular}{|c|c|c|}
\hline tube voltage (kv) & $\begin{array}{l}\text { tube current } \times \text { time } \\
\text { (mas) }\end{array}$ & $\begin{array}{l}\text { dose area product } \\
\left(\mathrm{cgy} \times \mathrm{cm}^{2}\right)\end{array}$ \\
\hline 81 & 191.0 & 757.0 \\
\hline 77 & 66.8 & 208.4 \\
\hline 77 & 14.9 & 40.7 \\
\hline 77 & 41.2 & 110.1 \\
\hline 77 & 111.0 & 318.9 \\
\hline 81 & 65.1 & 232.0 \\
\hline 81 & 49.4 & 246.0 \\
\hline 77 & 58.5 & 175.8 \\
\hline 77 & 23.2 & 61.0 \\
\hline \multirow[t]{2}{*}{77} & 98.7 & 308.0 \\
\hline & mean 72 & mean 245.79 \\
\hline
\end{tabular}

As the analysis of examinations of 10 additional patients demonstrated, this led to a DAP reduction by approx. $50 \%$ to $123 \pm 61.25 \mathrm{cGy} \cdot \mathrm{cm}^{2}$ for a lumbar spine (LSP) a-p examination and approx. $30 \%$ for a lateral LSP examination to $229 \pm 116.46 \mathrm{cGy} \cdot \mathrm{cm}^{2}$. Due to theoretical considerations this cannot be traced solely to the increase to $10 \mathrm{kV}$ tube charge, which resulted only in a dose reduction of $20-30 \%$ for patients of normal weight. Inspection of the images by two experienced observers indicated that the diagnostic image quality after this adjustment was not restricted ( $\bullet$ Fig. 5).

Another option to reduce the dose is to take into account the characteristics of X-ray images of patients with metallic prostheses. Depending of the position of the prosthesis 

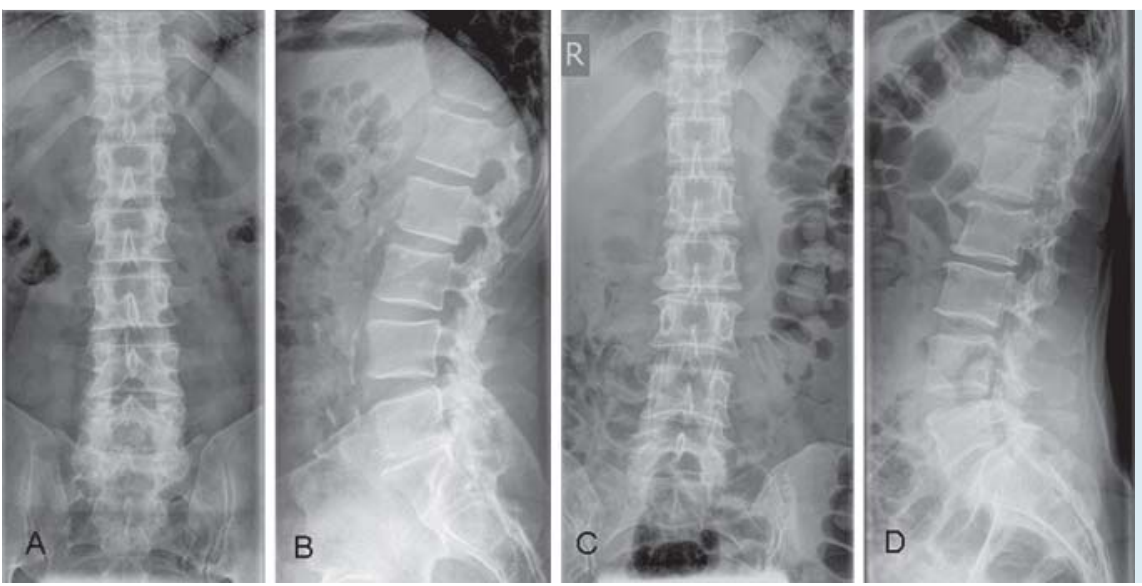

Fig. 5 X-ray of the a-p and lateral lumbar spine before A, B and after optimization C, D obtained from two different patients with comparable body weight (76 and $78 \mathrm{~kg}$ ) and height (172 and 168 $\mathrm{cm})$. Image quality is not reduced after optimization. Exposure was $62 \mathrm{cGy} \times \mathrm{cm}^{2}(\mathrm{a}-\mathrm{p})$ and $242 \mathrm{cGy} \times \mathrm{cm}^{2}$ (lateral) and after optimization $32 \mathrm{cGy} \times \mathrm{cm}^{2}(\mathrm{a}-\mathrm{p})$ and $58 \mathrm{cGy} \times \mathrm{cm}^{2}$ (lateral).

with respect to the X-ray chamber, the dose can under circumstances be increased, since the metal absorbs the radiation almost completely. Consequently the automatic exposure control incorrectly characterizes the image as underexposed and increases the exposure time. Therefore it is advisable in such cases to use manual exposure, as successfully practiced using the image plate system. This results, on average, in $123.54 \pm 5.94 \mathrm{cGy} \cdot \mathrm{cm}^{2}$ required for pelvis images using this equipment, about half the diagnostic reference level of $300 \mathrm{cGy} \cdot \mathrm{cm}^{2}$ specified in the German $\mathrm{X}$-ray Ordinance.

Further, the examination parameters for a lumbar spine examination using a 16-slice spiral CT unit were reviewed in detail. The examination parameters were as follows: tube voltage $120 \mathrm{kV}, \mathrm{mAs} 300$, pitch 0.56 , slice thickness $1.25 \mathrm{~mm}$, noise index 16.3.

Compared with BfS specifications, it could be seen that the DAP and CT dose index are increased, thus the optimization task was to adjust the parameters affecting $\mathrm{CTDI}_{\mathrm{Vol}}$. It was further observed that the average scan length for lumbar spine examinations on the CT unit in the department studied is significantly higher $(13 \mathrm{~cm})$ than the scan length specified by the BfS for determining the diagnostic reference level $(6 \mathrm{~cm})$. For this reason there was a consideration of how the selected scan length was justified by the clinical issue. However, this was always the case, and therefore the scan length could not be reduced.

Nagel's guidelines for the evaluation and optimization of radiation exposure for CT examinations [10] recommend a pitch of 1 and an image voltage of $140 \mathrm{kV}$ for lumbar spine examinations; due to high contrast, this provides sufficient image contrast for the observed object. Therefore the first optimization step was to increase the unusually low pitch. The second step was to increase the image acquisition voltage while correspondingly reducing the tube voltage. After each step, the change in dose was reviewed in a random sample of 10 examinations. In addition, image quality was assessed by two experienced radiologists after each optimization measure. First, operation of the automatic exposure control used in the GE unit was considered, since under some circumstances it could change other scan parameters when the pitch factor is altered. The automatic exposure control of GE units adjusts the tube current to the radiated volume so that the image quality remains constant for every slice. Image quality is hereby defined by the noise index; in
Table 7 Optimization steps for CT examinations of the lumbar spine on the 16-slice spiral CT scanner.

\begin{tabular}{|lllll|}
\hline optimization step & tube voltage (kV) & pitch & index & DLP \\
\hline original value & 120 & 0.56 & 16.3 & 840 \\
\hline $\begin{array}{l}\text { pitch increased } \\
\text { tube voltage and noise index } \\
\text { increased }\end{array}$ & 120 & 0.94 & 16.3 & 646 \\
\hline noise index increased & 140 & 0.94 & 20.3 & 512 \\
\hline
\end{tabular}

addition, minimum and maximum tube current is specified. Further, there is the option to use angle-dependent $(x-y-)$ tube current modulation.

In the first step, the pitch factor of 0.562 was increased to the next possible value of 0.938 ; the other scan parameters remained unchanged. The DLP was not thereby reduced by a factor of $1 / 3$, as would be assumed due to the linear correlation with the pitch factor. Because of the automatic dose control which maintained constant image quality, the reduction was only $1 / 4$ of the starting dose. Then the narrow field of view (FOV) was enlarged during the imaging to allow the automatic exposure control to select lower dose levels.

In the next step, the imaging voltage increased to $140 \mathrm{kV}$, but the image quality was reduced somewhat since the noise index increased. The noise index was further increased until the dose area product (DAP) was below the diagnostic reference level (DRL). The individual steps are summarized in Table 7. Since image noise increased only somewhat, the diagnostic value of the examinations was not influenced. Fig. 6 illustrates the example of a patient examined for clinical reasons before and after optimization. In the course of optimization the average DAP of the next 10 patients could be reduced by $50 \%$ to $421.50 \pm$ $241.06 \mathrm{mGy} \cdot \mathrm{cm}$, thus fulfilling the requirements of the BfS.

\section{Discussion \\ $\nabla$}

When establishing the diagnostic reference levels, the BfS selected the $75^{\text {th }}$ percentile of the mean dose levels reported by operators to the Medical Society [6]. This means that for the total reported levels for each examination type, $25 \%$ of the reported cases lie above the new diagnostic reference 

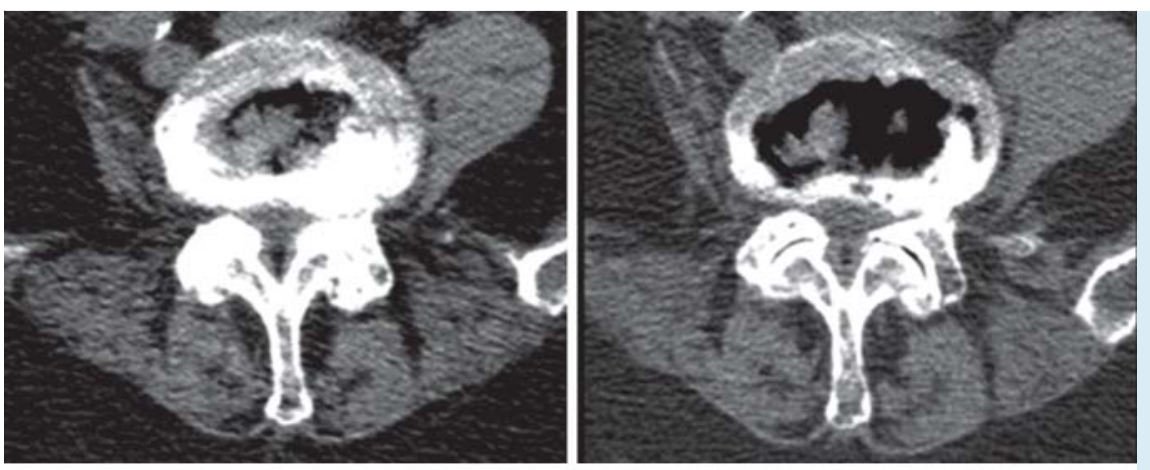

Fig. 6 Scan of the lumbar spine of the same patient before (left) and after optimization (right) obtained using a 16-slice spiral CT. Top: soft tissue window, axial, mid row: bone window, axial, bottom: reconstruction in sagittal plane, bone window. Dose of the scan was $804 \mathrm{mGy} \times \mathrm{cm}$ (DLP) before and $619 \mathrm{mGy} \times \mathrm{cm}(\mathrm{DLP})$ after optimization.
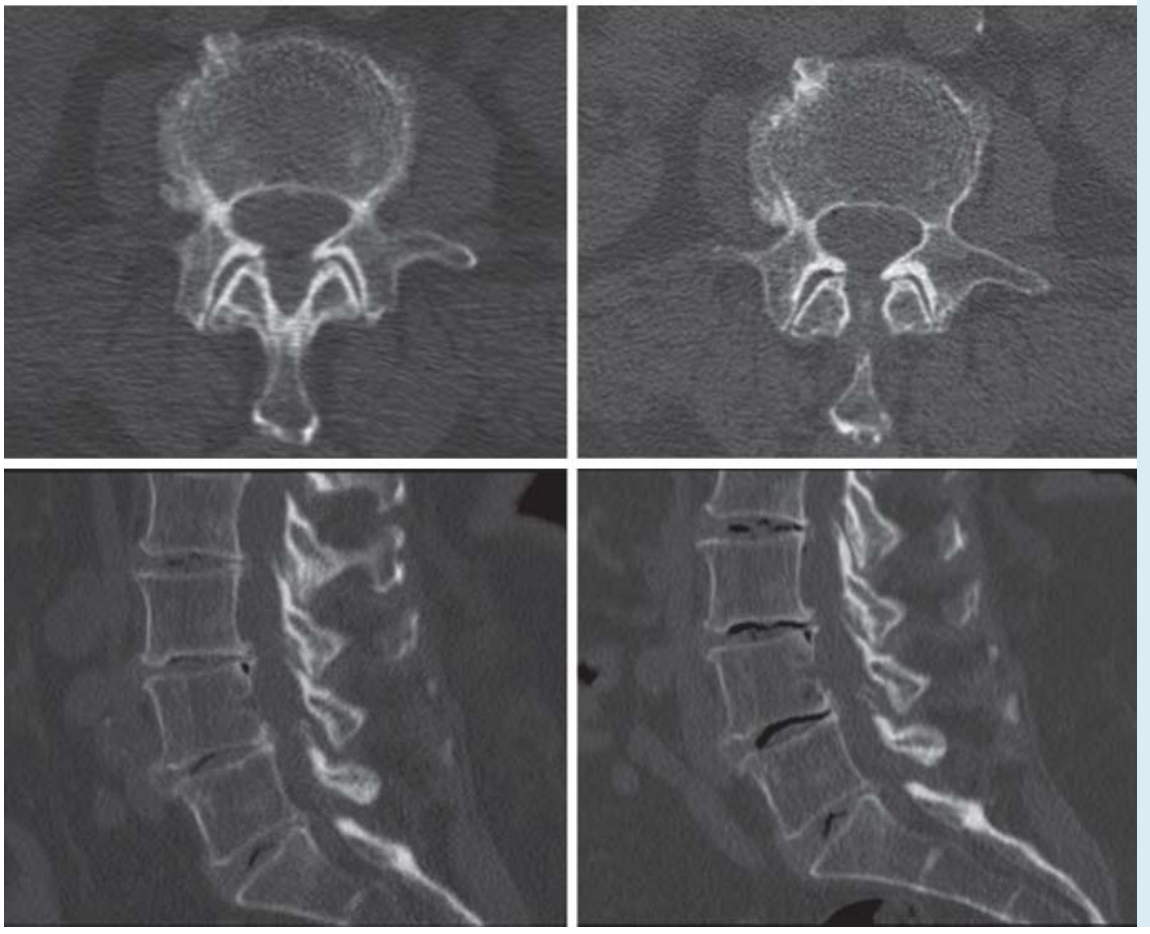

levels, assuming no change in imaging technology. Consequently, those operators whose dose levels on average are too high are instructed to lower the patient radiation exposure by optimizing their examination technique. In many cases this has been achieved by adjusting the imaging parameters while stringently controlling the resulting image quality. If optimizing the imaging technique nevertheless does not lower radiation exposure to normal weight patients below the specified diagnostic reference level limits, then this is a sign of obsolescence of a device. In such cases, the imaging unit must be retrofitted or replaced. In the long term, the selection of the $75^{\text {th }}$ percentile of values reported by the operators and periodic updating of the diagnostic reference levels have resulted in a steady reduction of patient radiation exposure, and have consequently been used as a strategy. The diagnostic reference levels published in 2003 did not use CTDI $_{w}$ or volume CTDI. The dose length product (DLP) was based on the entire examination In the diagnostic reference levels published in 2010, however, the volume CTDI was specified as a reference value and the DLP now applies only to a scan series. Various approaches can be used to optimize exposure conditions. A distinction should be made between actions that change image quality and those having no influence on image quality or which improve the quality. Collimation using an image intensifier reduces radiation exposure and can improve image quality, since less scattered radiation occurs in the patient's body due to the reduced exposed field $[11,12]$.

Additional options for examinations of adults include selection of the proper grid, accurate configuration of the automatic exposure control, and in the case of patients with metallic implants in the examination region, manual exposure should be used. Use of a grid should be omitted for children. Reduction of radiation exposure can also be achieved by employing auxiliary filters, adjusting tube voltage and applying appropriate sensitivity classes for film/plate systems or detectors corresponding to the guidelines of the German Medical Association [13]. Using a testicle pouch or ovarian shield further reduces genetic effects.

An unused opportunity for the operators of X-ray equipment to obtain information about the applied dose and to reduce the dose using appropriate measures lies in the analysis of the archived radiation exposure values of their own patients. Normally these values are documented for each patient according to statutory requirements; however they are rarely periodically reviewed internally or continuously monitored independently of the medical authority. Despite the common practice of pure archiving of exposure param- 
eters, operators rarely fully exploit the optimization potential with respect to dose reduction of their own equipment and patient clientele.

As a rule, when up-to-date equipment is used, the required dose for normal-weight patients lies well below diagnostic reference levels. If imaging equipment has been optimized with respect to image quality and radiation exposure at the time of installation, changes may occur in the course of months or years of operation, such as minor changes of imaging parameters, $\mathrm{mAs}$ and $\mathrm{kV}$, selection of dose measuring chamber or organ key assignment. If exposure values are not compared, these changes will not be observed, and consequently not corrected. Since even after a minor increase in levels, the values still remain below the diagnostic reference levels, the medical authority will not issue a warning, and the change in radiation exposure can remain unregarded. On the other hand, constant internal review of dose levels and the comparison with previously applied doses can detect whether deviations have occurred. In such cases, the next step must determine the cause of the increase in exposure levels and the operator should take appropriate measures to reduce dosages again. This enables dose management to actively utilize the raised values for the purposes of internal quality assurance.

Installation of an internal digital archive to record dose levels is a possible aid in simplifying these measures. In addition to exact documentation of the examination type and exposure level, the individual evaluation of the examination equipment is of importance. If the evaluation is not performed separately for each device and examination type, deviations of one unit might remain undetected until they result in an increase in mean values across several devices. Device-related assessment allows operators to detect tendencies among a number of devices, and if necessary introduce optimization measures on individual units. If a decision is made to apply optimization measures is based on an increase in exposure levels, then a targeted image inspection is indispensable. This simple inspection can reveal possible sources of error such as insufficient collimation or too strong contrast due to absent filtering, low tube voltage, or other image processing errors. Once the targeted image inspection has been completed, optimization measures of the equipment with respect to image parameters can be implemented.

Our own analyses as part of this article showed that the investigation of exposure levels by evaluating data stored in the RIS (Radiology Information System) can be performed without consideration of individual patient weight. During evaluation of a very small number of patients, a summation of normal weight and overweight patients with the purpose of forming an average value has occasionally resulted in too high exposure levels. This was shown during the observation of 10 consecutive patients during the accompanied examinations. Levels deviating upward in the case of high body weight could be identified in the course of analysis, and the results correspondingly interpreted. A high standard deviation of dose levels is a possible indication of this. If greater case numbers are assessed, the mean DAP or DLP value is a good indicator of the ability to evaluate radiation exposure; in this case, outliers average each other out. Familiarity with the examination equipment allows easy identification of existing optimization potential based on the mean DAP and DLP.

Optimization of radiation exposure levels in a large department or practice is labor-intensive, and thus time-intensive. X-ray equipment and CT scanners frequently have several hundred examination programs; a function for simple review and optimization of the equipment is generally only available to the service technician. In routine clinical practice, generally only a selection of the programs stored on the equipment is available for use. However, the basic principles of dose reduction must be applied when changing programs. Further, continuous monitoring in terms of dose management is important in order to detect and remedy via appropriate measures minimal changes occurring regularly in the clinical routine that can result in an increase of applied dosage.

Introducing a continuous strategy as described in this article long before the diagnostic reference levels are reached is worthwhile, since continuous monitoring of exposure levels provides awareness of the possibility of dose management beyond the purposes of archiving for review by the Medical Authority, as required by the X-ray Ordinance. Supporting computer programs can make a crucial contribution in turning current legally required dosage archiving into an active dosage management process [14]; currently a few pioneers are already developing such programs.

- Investigation of exposure levels by evaluating data stored in the RIS (Radiology Information System) can be performed irrespective of individual patient weight if a sufficiently large time frame is selected.

- During evaluation of a very small number of patients, a summation of normal weight and overweight patients with the purpose of forming an average value has occasionally resulted in too high exposure levels, since the diagnostic reference levels are based on patients with a weight of $70 \mathrm{~kg}$.

- Evaluation of exposure levels enable the transition from dosage archiving for the purposes of Medical Authority review with doses below diagnostic reference levels to active dose management including optimization of examination parameters.

\section{References}

1 Kemerink M, Dierichs TJ, Dierichs $J$ et al. The application of X-rays in radiology: from difficult and dangerous to simple and safe. Am J Roentgenol 2012; 198: 754-759

2 Kemerink M, Dierichs TJ, Dierichs J et al. Characteristics of a first-generation x-ray system. Radiology 2011; 259: 534-539

3 Internationale Strahlenschutzkommission. Strahlenschutz und Sicherheit in der Medizin. ICRP-Veröffentlichung 73; BfS-SCHR-1999; Bremerhaven: Wirtschaftsverlag/Verlag für neue Wissenschaft; 1999

4 Europäische Gemeinschaften. Richtlinie 97/43/EURATOM des Rates vom 30. Juni 1997 über den Gesundheitsschutz von Personen gegen die Gefahren ionisierender Strahlung bei medizinischer Exposition und zur Aufhebung der Richtlinie 84/466/EURATOM. ABl. L Nr. 18022

5 European Commission. Radiation Protection 109, Guidance on diagnostic reference levels (DRLs) for medical exposures. Luxembourg: Office for Official Publications of the European Communities; 1999

6 Verordnung über den Schutz vor Schäden durch Röntgenstrahlen (Röntgenverordnung -RöV) vom 8. Januar 1987 (BGBl. I S. 114) in der Fassung der Bekanntmachung vom 30. April 2003 (BGBl. I S 604)

7 Bekanntmachung der aktualisierten diagnostischen Referenzwerte. http://www.bfs.de/ion/medizin/referenzwerte.html

8 Veit $R$, Guggenberger R, Nosske D et al. Diagnostic reference levels for X-ray examinations: update 2010. Radiologe 2010; 50: 907 -912 
9 Bundesamt für Strahlenschutz. Pressemitteilung 12 vom 29.7.2010; www.bfs.de/de/bfs/presse/pr10/pr1210.html (abgerufen am 16.10.2013)

10 Nagel HD, Vogel H. Leitfaden zur Bewertung und Optimierung der Strahlenexposition bei CT-Untersuchungen. 3.Auflage2010 www. sascrad/de/attachments/File/Leitfaden_CT_(Ed_3).pdf (abgerufen am 16.10.2013)

11 Rimpler A, Veit R, Nosske D et al. Radiation hygiene in medical X-ray imaging, part 1: physical and technical basics. Radiologe 2010; 50: $809-820$
12 Brix G, Veit R, Häusler $U$. Radiation hygiene in medical X-ray imaging: part 2: Assessment of radiation exposure and radiation protection measures. Radiologe 2010; 50: 913-925

13 Bundesärztekammer. Leitlinien der Bundesärztekammer zur Qualitätssicherung in der Röntgendiagnostik - Qualitätskriterien röntgendiagnostischer Untersuchungen (2007). www.bundesaerztekammer. de/downloads/LeitRoentgen2008korr2.pdf (abgerufen am 16.10.2013)

14 Seuri R, Rehani MM, Kortesniemi M. How tracking radiologic procedures and dose helps: experience from Finland. Am J Roentgenol 2013; 200: $771-775$ 